\title{
Effects of pioglitazone and metformin on NEFA-induced insulin resistance in type 2 diabetes
}

\author{
R. Basu • A. Basu $\cdot$ V. Chandramouli $\cdot$ B. Norby $\cdot$ \\ B. Dicke • P. Shah • O. Cohen • B. R. Landau • \\ R. A. Rizza
}

Received: 21 July 2008 /Accepted: 23 July 2008 / Published online: 4 September 2008

(C) Springer-Verlag 2008

\begin{abstract}
Aims/hypothesis We sought to determine whether pioglitazone and metformin alter NEFA-induced insulin resistance in type 2 diabetes and, if so, the mechanism whereby this is effected.

Methods Euglycaemic-hyperinsulinaemic clamps (glucose $\sim 5.3 \mathrm{mmol} / \mathrm{l}$, insulin $\sim 200 \mathrm{pmol} / \mathrm{l})$ were performed in the presence of Intralipid-heparin (IL/H) or glycerol before and after 4 months of treatment with pioglitazone $(n=11)$ or metformin $(n=9)$ in diabetic participants. Hormone secretion was inhibited with somatostatin in all participants.

Results Pioglitazone increased insulin-stimulated glucose disappearance $(p<0.01)$ and increased insulin-induced suppression of glucose production $(p<0.01)$, gluconeogenesis $(p<0.05)$ and glycogenolysis $(p<0.05)$ during $\mathrm{IL} / \mathrm{H}$. However, glucose disappearance remained lower $(p<0.05)$
\end{abstract}

B. R. Landau died after the completion of this study.

R. Basu $\cdot$ A. Basu $\cdot$ B. Norby $\cdot$ B. Dicke $\cdot$ R. A. Rizza $(\triangle)$

Division of Endocrinology, Diabetes,

Metabolism and Nutrition, Mayo Clinic College of Medicine,

2001 st Street SW, Room 5-194 Joseph,

Rochester, MN 55905, USA

e-mail: rizza.robert@mayo.edu

V. Chandramouli $\cdot$ B. R. Landau

Division of Clinical and Molecular Endocrinology,

Case Western Reserve University School of Medicine,

Cleveland, OH, USA

P. Shah

Department of Endocrine Neoplasia and Hormonal Disorders, University of Texas MD Anderson Cancer Center,

Houston, TX, USA

O. Cohen

Institute of Endocrinology, Chaim Sheba Medical Center,

Tel Hashomer, Israel whereas glucose production $(p<0.01)$, gluconeogenesis $(p<0.05)$ and glycogenolysis $(p<0.05)$ were higher on the IL/H study day than on the glycerol study day, indicating persistence of NEFA-induced insulin resistance. Metformin increased $(p<0.001)$ glucose disappearance during $\mathrm{IL} / \mathrm{H}$ to rates present during glycerol treatment, indicating protection against NEFA-induced insulin resistance in extrahepatic tissues. However, glucose production and gluconeogenesis (but not glycogenolysis) were higher $(p<0.01)$ during $\mathrm{IL} / \mathrm{H}$ than during glycerol treatment with metformin, indicating persistence of NEFA-induced hepatic insulin resistance.

Conclusions/interpretation We conclude that pioglitazone improves both the hepatic and the extrahepatic action of insulin but does not prevent NEFA-induced insulin resistance. In contrast, whereas metformin prevents NEFAinduced extrahepatic insulin resistance, it does not protect against NEFA-induced hepatic insulin resistance.

Keywords Gluconeogenesis · Glycogenolysis · Insulin resistance $\cdot$ Non-esterified fatty acids $\cdot$ Metformin .

Thiazolidinediones Type 2 diabetes

Abbreviations
IL/H Intralipid-heparin
FFM fat-free mass

\section{Introduction}

Metformin and thiazolidinediones are commonly used to treat people with type 2 diabetes. Both are considered to be insulin sensitisers [1-3]. While these agents exert multiple effects in many tissues, they are believed to act, at least in part, by mitigating NEFA-induced insulin resistance [4-7]. However, not all data support this conclusion. Fasting 
plasma NEFA concentrations were lower following treatment with metformin or thiazolidinediones in many [8-10] but not all [11-15] studies. Insulin resistance produced by a lipid infusion is prevented by thiazolidinediones in rodents $[4,16,17]$ but not in humans $[18,19]$. In addition, even the data in rodents are not concordant. Hevener et al. reported that troglitazone prevented NEFA-induced hepatic and extrahepatic insulin resistance when NEFA concentrations prior to and during treatment were matched by a lipid infusion [16]. In contrast, Ye et al., using a similar experimental design, reported that whereas pioglitazone improved insulininduced suppression of glucose production, NEFA continued to impair insulin-induced stimulation of glucose disposal [17]. In addition, Ye et al. demonstrated that treatment with metformin prevented lipid-induced hepatic insulin resistance but did not prevent NEFA-induced impairment of muscle glucose uptake [4].

To our knowledge, there are no studies that have compared the ability of metformin and a thiazolidinedione to prevent NEFA-induced insulin resistance in people with type 2 diabetes. The present study sought to address this question.

\section{Methods}

Subjects After approval of the study by the Mayo Clinic Institutional Review Board, 31 participants with type 2 diabetes mellitus gave informed written consent to participate in the study. All participants were in good health and at a stable weight. None regularly engaged in vigorous physical exercise. Patient characteristics and results of the glycerol control studies have been published previously [20]. The present report is based on the results obtained in the 20 participants in whom paired Intralipid-heparin (IL/H) and glycerol data were available both before and after treatment. Pretreatment data were not available in eight participants because of ex vivo lipolysis, which precluded accurate measurement of NEFA concentrations, and in three participants because of persistent labelling of C5 glucose with ${ }^{2} \mathrm{H}$ from a previous study. However, as noted in the Discussion, conclusions regarding the effects of pioglitazone and metformin on NEFA-induced insulin resistance were the same when both the pre- and posttreatment data were analysed in the 20 participants or only the post-treatment data (available in all participants) were analysed in the 31 participants (data not shown).

Of the 11 participants in the pioglitazone group, five had been treated previously with metformin alone, one with sulfonylurea alone, two with a combination of metformin and sulfonylurea, and three with diet alone. Of the nine participants in the metformin group, seven had been treated previously with metformin alone, one with sulfonylurea alone, and one with a combination of metformin and sulfo- nylurea. Oral hypoglycaemic medications were discontinued at least 10 days prior to the pretreatment study visit. Following completion of the pretreatment study, participants were randomly assigned (in a double-blind, double-placebo controlled design) to receive either pioglitazone (45 mg daily) or metformin (1000 mg twice daily) for 4 months. Following randomisation, participants received daily doses of either pioglitazone $45 \mathrm{mg}$ or metformin 2,000 $\mathrm{mg}$ for 4 months the last dose being given the day before the study. Subjects continued to receive pioglitazone or metformin during the post-treatment study, i.e., study drugs were not discontinued during the evening before the study and the morning of the study. Also, each participant took their regular and study medications as prescribed. Subjects on stable doses of thyroxine, oestrogen replacement therapy, 3-hydroxy-3-methylglutaryl coenzyme A reductase inhibitors and metabolically neutral antihypertensive medications (low-dose thiazide, calcium channel blockers or losartan) continued these medicines during the study.

Experimental design Subjects were admitted to the Mayo Clinical Research Unit at 17:00 hours on the evening before the study, fed a standard meal, and given $1.67 \mathrm{~g}^{2} \mathrm{H}_{2} \mathrm{O} / \mathrm{kg}$ fat-free mass (FFM) of body water at 18:00, 20:00 and 22:00 hours, as described previously [20]. An infusion of insulin was started after the standard meal, adjusted to maintain glucose concentrations at $\sim 5 \mathrm{mmol} / \mathrm{l}$ during the night. An infusion of either Intralipid (Baxter Healthcare, Deerfield, IL, USA; $20 \%$ infused at $0.008 \mathrm{ml}^{[\mathrm{kg} \mathrm{FFM}]^{-1}}$ $\mathrm{min}^{-1}$ for men and $0.014 \mathrm{ml}[\mathrm{kg} \mathrm{FFM}]^{-1} \mathrm{~min}^{-1}$ for women) and heparin (200 $\mathrm{U}$ prime, $0.2 \mathrm{U} \mathrm{kg}^{-1} \mathrm{~min}^{-1}$ continuous) or glycerol $\left(6.8 \mu \mathrm{mol} \mathrm{kg} \mathrm{min}^{-1}\right)$ was started at 06:00 hours. The IL/H infusion was unchanged following treatment with metformin but increased by $\sim 30 \%$ (to $0.011 \mathrm{ml}[\mathrm{kg} \mathrm{FFM}]^{-1}$ $\min ^{-1}$ for men and $0.018 \mathrm{ml}[\mathrm{kg} \mathrm{FFM}]^{-1} \mathrm{~min}^{-1}$ for women) after treatment with pioglitazone. The $\mathrm{IL} / \mathrm{H}$ and glycerol experiments were performed in random order and separated by at least 21 days.

On each occasion, a primed (fasting glucose in $\mathrm{mmol} / \mathrm{l}$ divided by $5.5 \mathrm{mmol} / 1$ multiplied by $0.44 \mathrm{MBq}$ ), continuous $\left(0.0044 \mathrm{MBq} / \mathrm{min}\right.$ ) infusion of $\left[3-{ }^{3} \mathrm{H}\right]$ glucose (Perkin Elmer, Boston, MA, USA) was started at 07:00 hours. Infusions of insulin $\left(0.6 \mathrm{mU} \mathrm{kg}{ }^{-1} \mathrm{~min}^{-1}\right)$, somatostatin $\left(60 \mathrm{ng} \mathrm{kg}^{-1}\right.$ $\left.\mathrm{min}^{-1}\right)$, growth hormone $\left(3 \mathrm{ng} \mathrm{kg}{ }^{-1} \mathrm{~min}^{-1}\right)$ and glucagon $\left(0.65 \mathrm{ng} \mathrm{kg}^{-1} \mathrm{~min}^{-1}\right.$ ) were started at 10:00 hours (time $0 \mathrm{~min})$. An infusion of $\left[9,11,12,12-{ }^{2} \mathrm{H}_{4}\right]$ cortisol was started at 06:00 hours as part of a separate protocol. Beginning at 09:30 hours, a solution containing $\left[3{ }^{3} \mathrm{H}\right]$ glucose was infused in amounts sufficient to maintain plasma glucose concentration at $\sim 5 \mathrm{mmol} / \mathrm{l}$.

Analytical techniques Samples were placed in ice, centrifuged at $4{ }^{\circ} \mathrm{C}$, separated, and stored at $-20^{\circ} \mathrm{C}$ until analysis. 
Samples for NEFA were collected in tubes containing $50 \mu \mathrm{l}$ diethyl-p-nitrophenyl-phosphate (Paraoxon; Sigma Chemicals, St Louis, MO, USA) diluted to $0.04 \%$ in diethyl ether to prevent ex vivo lipolysis. Plasma glucose, insulin, Cpeptide and glucagon concentrations, $\left[3-{ }^{3} \mathrm{H}\right]$ glucose specific activity, and enrichment of ${ }^{2} \mathrm{H}$ on the second and fifth carbon atoms of plasma glucose were measured as described previously $[20,21]$. Plasma glycerol and NEFA concentrations were measured by a modified microfluorometric enzymatic method [22].

Calculations Rates are expressed as $\mu \mathrm{mol}(\mathrm{kg} \mathrm{FFM})^{-1} \mathrm{~min}^{-1}$. Basal and clamp responses were assessed by taking the mean of the values present from -30 to $0 \mathrm{~min}$ and from 270 to 300 min respectively. Glucose appearance and disappearance were calculated using the steady-state equations of Steele et al. [23]. Endogenous glucose production during the clamp was calculated by subtracting the exogenous glucose infusion rate from the total glucose appearance rate. The rate of gluconeogenesis was calculated by multiplying the plasma ratio of $\mathrm{C} 5$ and $\mathrm{C} 2$ glucose enrichment times by endogenous glucose production [24]. Glycogenolysis was calculated by subtracting the rate of gluconeogenesis from endogenous glucose production.

Statistical analysis Data in the text and figures are expressed as mean \pm SEM. Student's paired $t$ test was used to test the primary hypothesis that insulin action was less following treatment on the $\mathrm{IL} / \mathrm{H}$ than on the glycerol study days. While this is a one-sided hypothesis, two-sided $p$ values are reported in the text and figures to be conservative. Student's $t$ test was also used to test the secondary hypotheses that insulin action increased following treatment and that insulin action before treatment differed on the $\mathrm{IL} / \mathrm{H}$ and glycerol study days. A $p$ value of less than 0.05 was considered statistically significant.

\section{Results}

Subject characteristics Subject characteristics are provided in Table 1. Age, sex, weight, BMI, lean body mass, body fat percentage, visceral fat, fasting plasma glucose, $\mathrm{HbA}_{1 \mathrm{c}}$ and years since diagnosis of diabetes did not differ between groups before treatment. Body weight, BMI and body fat percentage were higher $(p<0.05)$ with pioglitazone treatment but remained unchanged with metformin treatment.

Plasma glucose, insulin, C-peptide and glucagon concentrations Plasma glucose concentrations did not differ on the $\mathrm{IL} / \mathrm{H}$ and glycerol study days before or after treatment with either pioglitazone or metformin (Fig. 1).

Plasma insulin concentrations were higher $(p<0.05)$ before the clamp on the $\mathrm{IL} / \mathrm{H}$ study day than on the glycerol study day before treatment, but did not differ after treatment with either agent. Plasma insulin concentrations did not differ during the clamps on the IL/H and glycerol study days on any occasion.

Plasma C-peptide concentrations did not differ before the clamps on the IL/H and glycerol study days in either group and were promptly and similarly suppressed during the clamps by the somatostatin infusion on all occasions.

Plasma glucagon concentrations were higher $(p<0.05)$ before the clamp on the IL/H study day than on the glycerol study day before treatment with either agent, but were no different after treatment. Glucagon concentrations did not differ during the clamp on any occasion.

Plasma NEFA and glycerol concentrations Plasma NEFA concentrations were not different before treatment with either pioglitazone or metformin on the IL/H $(1.1 \pm 0.3$ vs $0.9 \pm 0.2 \mathrm{mmol} / \mathrm{l})$ and glycerol $(0.4 \pm 0.1 \mathrm{vs} 0.3 \pm 0.1 \mathrm{mmol} / \mathrm{l})$ study days. Similarly, plasma NEFA concentrations were not different after treatment with either pioglitazone or

Table 1 Participant characteristics

\begin{tabular}{|c|c|c|c|c|}
\hline \multirow[t]{2}{*}{ Variable } & \multicolumn{2}{|c|}{ Before treatment } & \multicolumn{2}{|c|}{ After treatment } \\
\hline & Pioglitazone & Metformin & Pioglitazone & Metformin \\
\hline Participants (men/women) & $7 / 4$ & $6 / 3$ & & \\
\hline Age (years) & $56 \pm 3$ & $60 \pm 3$ & $57 \pm 3$ & $60 \pm 3$ \\
\hline Weight (kg) & $93.3 \pm 5.2$ & $89.6 \pm 4.6$ & $98.1 \pm 6.1^{*}$ & $89.9 \pm 4.5$ \\
\hline BMI $\left(\mathrm{kg} / \mathrm{m}^{2}\right)$ & $33.0 \pm 2.0$ & $32.4 \pm 1.4$ & $34.7 \pm 2.3^{*}$ & $32.6 \pm 1.5$ \\
\hline Lean body mass (kg) & $51.1 \pm 3.1$ & $47.6 \pm 3.7$ & $52.0 \pm 3.0$ & $48.6 \pm 3.6$ \\
\hline Body fat $(\%)$ & $39.7 \pm 2.9$ & $40.8 \pm 3.2$ & $41.6 \pm 3.0^{*}$ & $40.9 \pm 3.1$ \\
\hline Visceral fat $\left(\mathrm{cm}^{2}\right)$ & $212 \pm 27$ & $217 \pm 35$ & $219 \pm 25$ & $216 \pm 37$ \\
\hline Fasting glucose $(\mathrm{mmol} / \mathrm{l})$ & $8.7 \pm 0.8$ & $8.7 \pm 1.1$ & $7.3 \pm 0.6$ & $7.3 \pm 0.5$ \\
\hline $\mathrm{HbA}_{1 \mathrm{c}}(\%)$ & $6.7 \pm 0.3$ & $6.5 \pm 0.2$ & $6.3 \pm 0.2$ & $6.8 \pm 0.4$ \\
\hline Time since diagnosis of diabetes (years) & $6.8 \pm 1.0$ & $6.6 \pm 1.4$ & & \\
\hline
\end{tabular}

${ }^{*} p<0.05$ before vs after treatment 
a

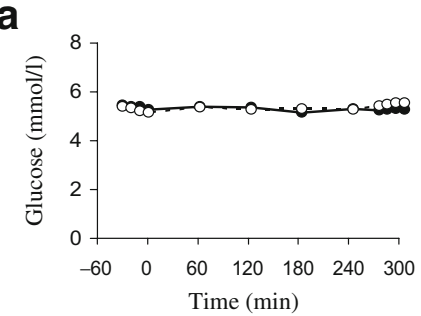

C

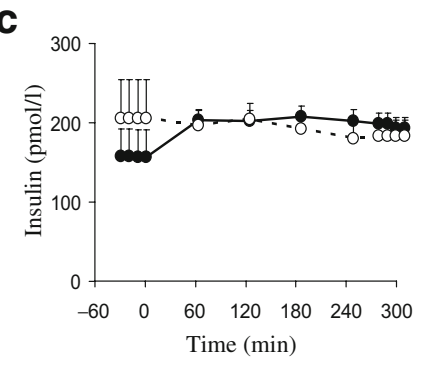

e

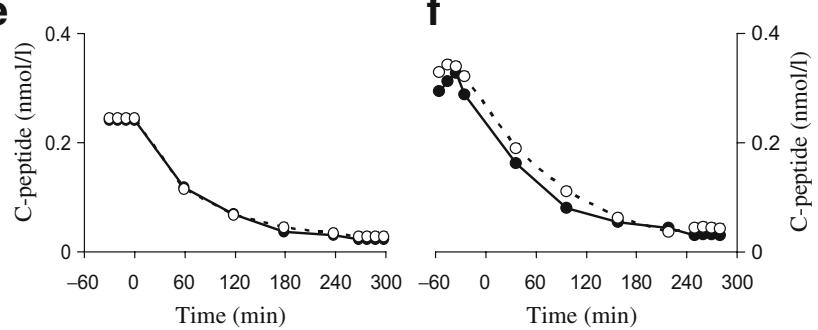

g

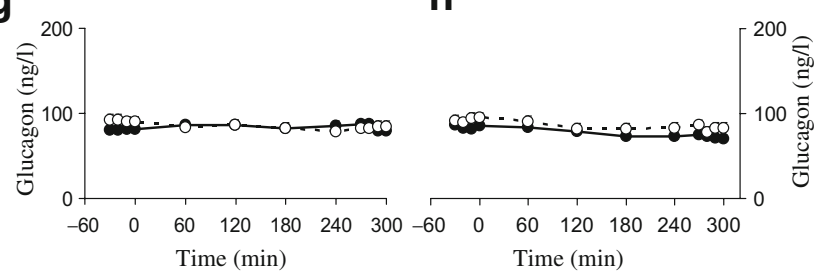

Fig. 1 Glucose, insulin, C-peptide and glucagon concentrations during infusion of Intralipid and heparin (white circles) or glycerol (black circles). Studies were performed before $(\mathbf{a}, \mathbf{c}, \mathbf{e}, \mathbf{g}, \mathbf{i}, \mathbf{k}, \mathbf{m}, \mathbf{o})$

metformin on the $\mathrm{IL} / \mathrm{H}(0.7 \pm 0.1$ vs $0.8 \pm 0.1 \mathrm{mmol} / \mathrm{l})$ and glycerol $(0.4 \pm 0.1$ vs $0.4 \pm 0.1 \mathrm{mmol} / \mathrm{l})$ study days. Plasma NEFA concentrations were higher $(p<0.05)$ on the IL/H than glycerol study days both before and after treatment with pioglitazone. Plasma NEFA concentrations were higher $(p<0.05)$ on the $\mathrm{IL} / \mathrm{H}$ than on the glycerol study days both before and after treatment with metformin (Fig. 2).

Plasma glycerol concentrations did not differ on the $\mathrm{IL} / \mathrm{H}$ or glycerol study days either before or after treatment with either agent.

Glucose disappearance Glucose disappearance during the clamp was lower $(p<0.05)$ on the IL/H than on the glycerol study day both before and after treatment with pioglitazone,
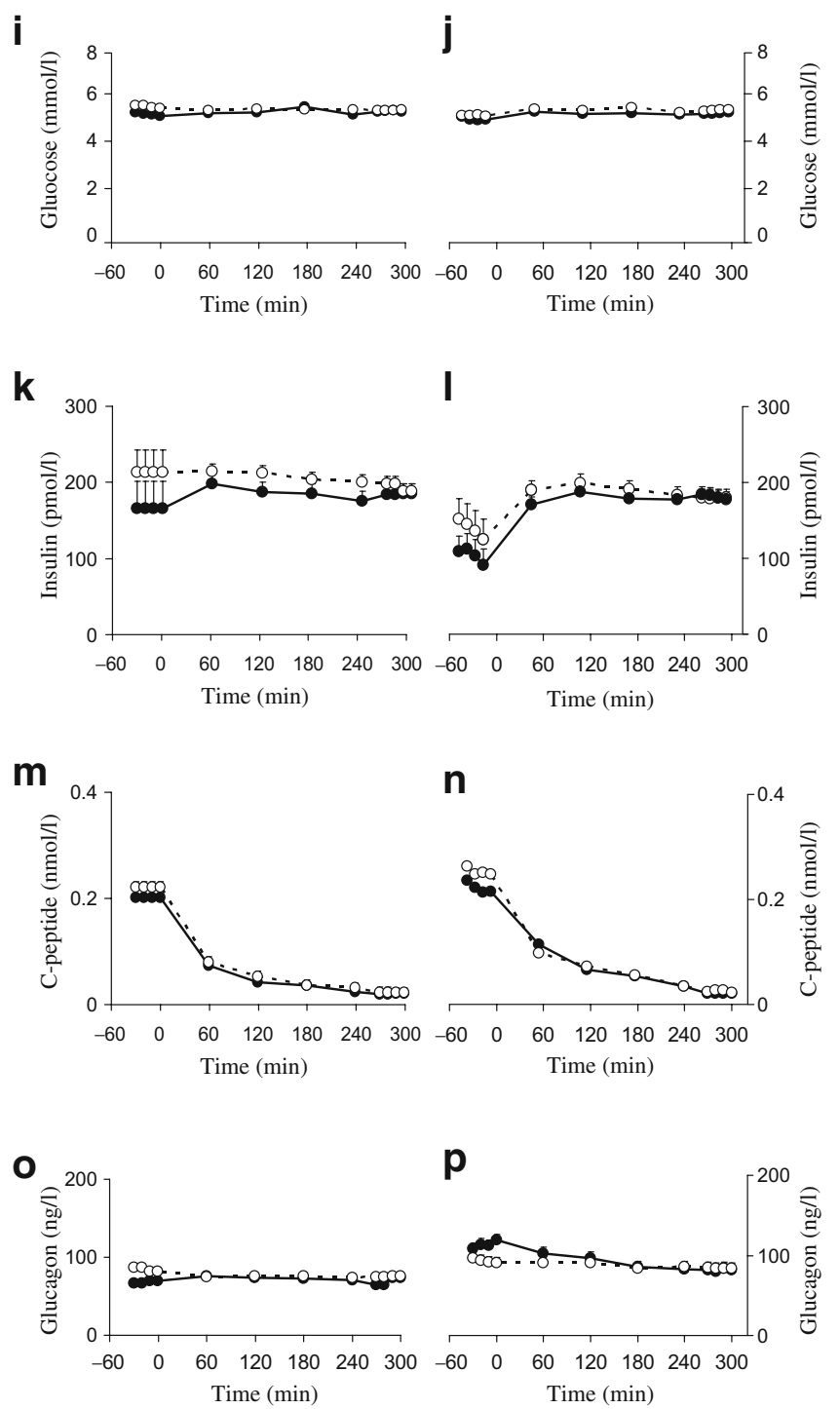

and after (b, d, f, h, j, l, n, p) 4 months of treatment with pioglitazone $(\mathbf{a}-\mathbf{h})$ or metformin (i-p). Infusion of insulin, somatostatin and glucagon was started at time zero

indicating that NEFA impaired insulin-induced stimulation of glucose disposal on both occasions. On the other hand, glucose disappearance during the clamp on the IL/H study day was higher $(p<0.01)$ after than before treatment. Of note, glucose disappearance during the clamp on the IL/H study day after treatment with pioglitazone did not differ from glucose disappearance on the glycerol study day prior to treatment with pioglitazone (Fig. 3).

Glucose disappearance during the clamp was lower on the IL/H than the glycerol study day before $(p<0.01)$ but not after treatment with metformin, indicating that metformin protected against NEFA-induced extrahepatic insulin resistance. In addition, glucose disappearance during the clamp on the IL/H study day was higher $(p<0.001)$ after treatment than before treatment with metformin, indicating 
a

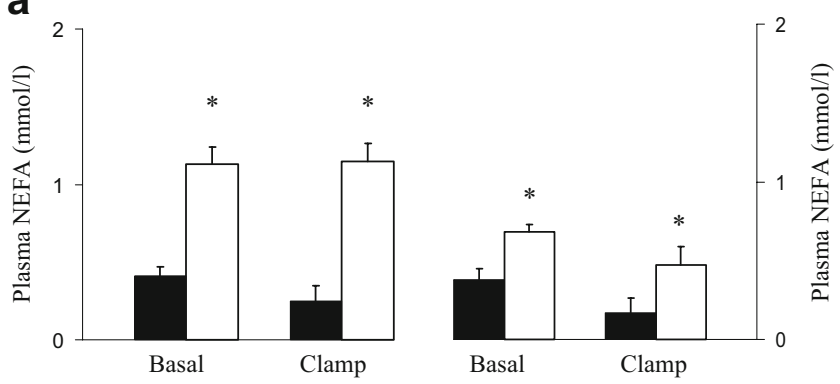

b

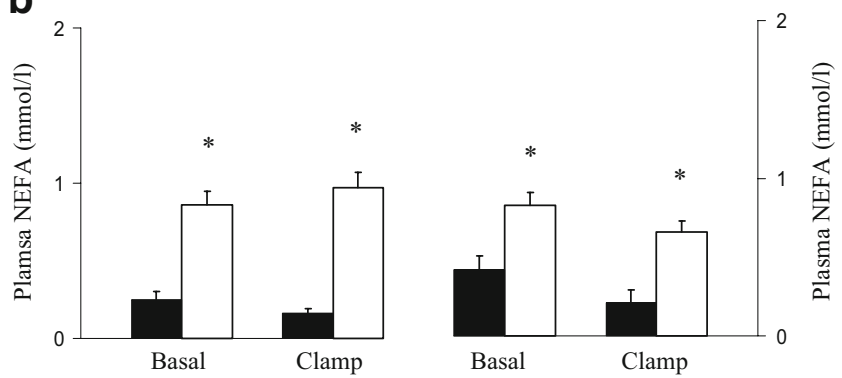

C
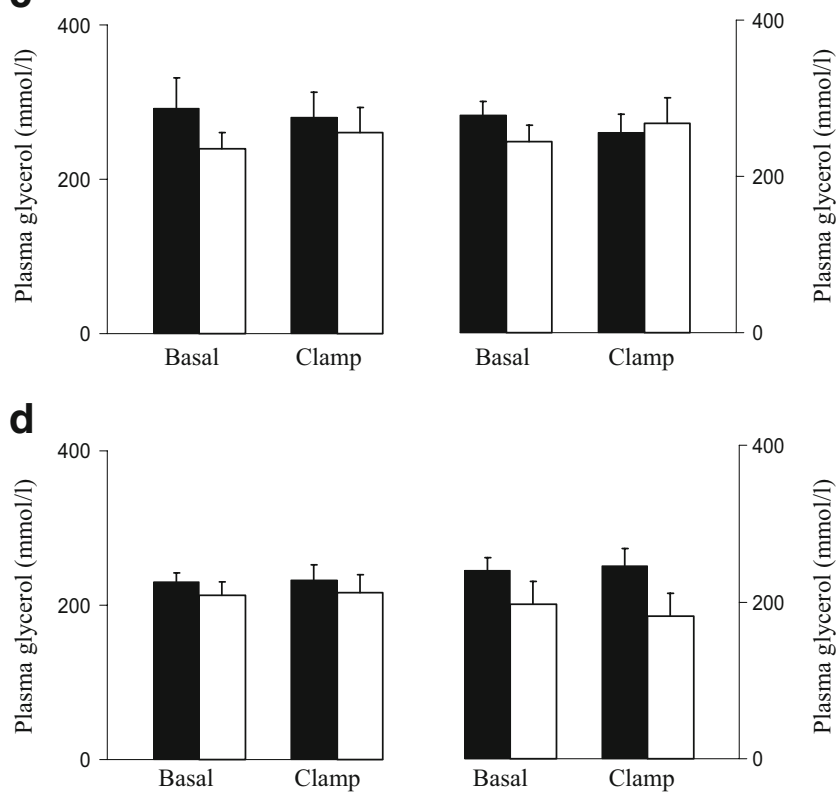

Fig. 2 Plasma NEFA (a, b) and glycerol $(\mathbf{c}, \mathbf{d})$ concentrations during infusion of Intralipid and heparin (white bars) or glycerol (black bars) before (basal) and during (clamp) a hyperinsulinaemic-euglycaemic clamp. Studies were performed before (left panels) and after (right panels) 4 months of treatment with pioglitazone (a, c) or metformin $(\mathbf{b}, \mathbf{d}) .{ }^{*} p<0.05$ vs glycerol study day

improved extrahepatic insulin action. As with pioglitazone, glucose disappearance during the clamp on the IL/H study day after treatment with metformin did not differ from glucose disappearance on the glycerol study day prior to treatment with metformin.

Endogenous glucose production Glucose production during the clamp was slightly but not significantly higher on the
IL/H than on the glycerol study day before treatment and significantly higher $(p<0.01)$ after treatment with pioglitazone, indicating that NEFA induced hepatic insulin resistance. However, glucose production during the clamp was lower after treatment than before treatment with pioglitazone on both the $\mathrm{IL} / \mathrm{H}(p<0.05)$ and glycerol $(p<0.01)$ study days, indicating improved hepatic insulin action. In addition, glucose production on the $\mathrm{IL} / \mathrm{H}$ study day after treatment with pioglitazone was lower $(p<0.05)$ than glucose production on the glycerol study day before treatment with pioglitazone. Thus, while pioglitazone improved hepatic insulin action, it did not prevent NEFAinduced hepatic insulin resistance (Fig. 4).

Glucose production during the clamp was higher on the $\mathrm{IL} / \mathrm{H}$ than on the glycerol study day both before $(p<0.05)$ and after $(p<0.01)$ treatment with metformin, indicating that NEFA induced hepatic insulin resistance. On the other hand, glucose production before treatment with metformin did not differ from that after treatment with metformin on either the $\mathrm{IL} / \mathrm{H}$ or the glycerol study day, indicating no improvement in hepatic insulin action.

Gluconeogenesis Gluconeogenesis during the clamp was higher $(p<0.05)$ on the IL/H than on the glycerol study day after treatment with pioglitazone, indicating that pioglitazone did not prevent NEFA-induced hepatic insulin

\section{a}

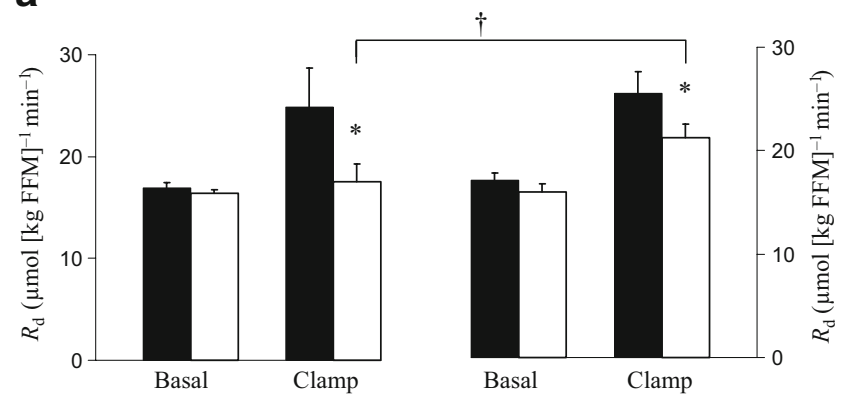

b

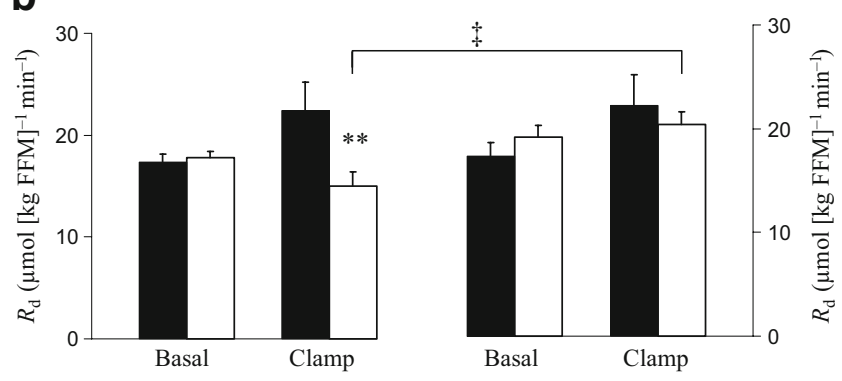

Fig. 3 Rates of glucose disappearance $\left(R_{\mathrm{d}}\right)$ before (basal) and during (clamp) a hyperinsulinaemic-euglycaemic clamp during infusion of Intralipid and heparin (white bars) or glycerol (black bars). Studies were performed before (left panels) and after (right panels) 4 months of treatment with pioglitazone (a) or metformin (b). ${ }^{*} p<0.05,{ }^{* *} p<$ 0.01 vs glycerol study day; ${ }^{\dagger} p<0.01,{ }^{\dagger} p<0.001$ 
a

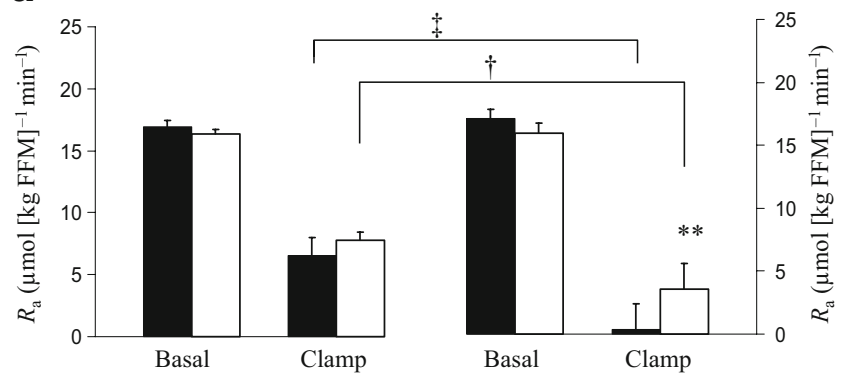

b

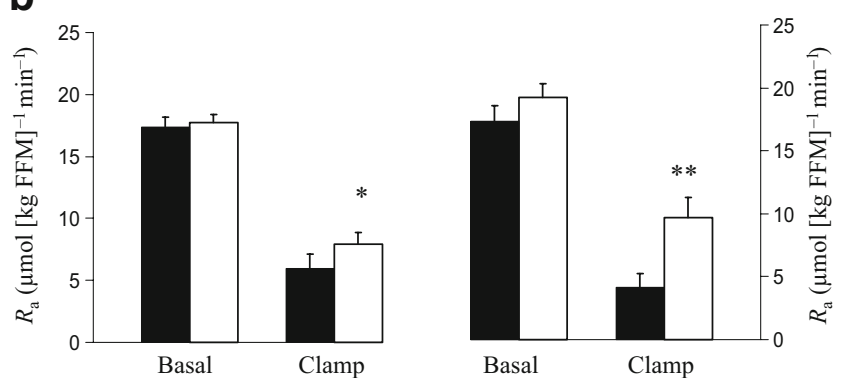

Fig. 4 Rates of endogenous glucose production $\left(R_{\mathrm{a}}\right)$ before (basal) and during (clamp) a hyperinsulinaemic-euglycaemic clamp during infusion of Intralipid and heparin (white bars) or glycerol (black bars). Studies were performed before (left panels) and after (right panels) 4 months of treatment with pioglitazone (a) or metformin (b). ${ }^{*} p<0.05$, ${ }^{* *} p<0.01$ vs glycerol study day; ${ }^{\dagger} p<0.05,{ }^{\star} p<0.01$

resistance. On the other hand, gluconeogenesis during the clamp was lower after treatment than before treatment with pioglitazone on both the IL/H $(p<0.05)$ and glycerol $(p<0.01)$ study days, indicating that pioglitazone improved hepatic insulin action in both the presence and absence of elevated NEFA concentration (Fig. 5).

Gluconeogenesis during the clamp did not differ on the $\mathrm{IL} / \mathrm{H}$ and the glycerol study day before treatment with metformin. In contrast, gluconeogenesis during the clamp was higher $(p<0.01)$ after treatment with metformin on the $\mathrm{IL} / \mathrm{H}$ than the glycerol study, indicating that NEFA induced hepatic insulin resistance. In addition, gluconeogenesis both before and during the clamp was higher $(p<0.05)$ after treatment than before treatment with metformin on the IL/H study day, indicating lack of improvement in hepatic insulin action.

Glycogenolysis Glycogenolysis during the clamp was higher $(p<0.05)$ on the IL/H than on the glycerol study day after treatment with pioglitazone, indicating that NEFA induced insulin resistance. Compared with pretreatment rates, glycogenolysis during the clamp was lower $(p<0.05)$ after treatment than before treatment with pioglitazone on both the $\mathrm{IL} / \mathrm{H}$ and the glycerol study day. In contrast, glycogenolysis after treatment with metformin did not differ on the IL/H and glycerol study days and did not differ from that observed before treatment with metformin (Fig. 6).

\section{Discussion}

People with type 2 diabetes are commonly insulin-resistant and have elevated NEFA concentrations $[9,11,13,25]$. The present studies indicate that both pioglitazone and metformin modulate fat-induced insulin resistance. However, this effect occurs via different mechanisms. Pioglitazone enhanced insulin-induced stimulation of glucose uptake and suppression of glucose production in the presence as well as in the absence of elevated NEFA. However, pioglitazone did not protect against either NEFA-induced hepatic or extrahepatic insulin resistance, since glucose disappearance was lower and endogenous glucose production, gluconeogenesis and glycogenolysis were all higher during the $\mathrm{IL} / \mathrm{H}$ than the glycerol infusion after 4 months of treatment with pioglitazone. In contrast, whereas treatment with metformin prevented NEFA-induced extrahepatic insulin resistance, it did not protect against NEFA-induced hepatic insulin resistance.

Effects of pioglitazone on NEFA-induced insulin resistance The present data resolve several apparent inconsistencies in the literature and emphasise the importance of including appropriate control studies so that insulin action in the presence of elevated NEFA can be directly compared with

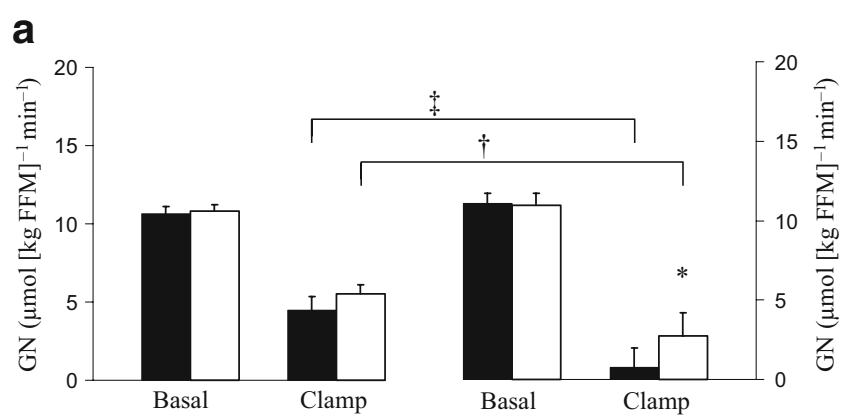

b

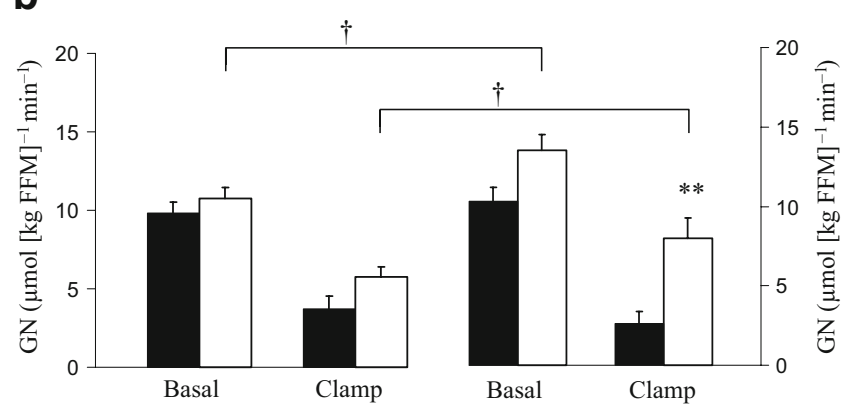

Fig. 5 Rates of gluconeogenesis (GN) before (basal) and during (clamp) a hyperinsulinaemic-euglycaemic clamp during infusion of Intralipid and heparin (white bars) or glycerol (black bars). Studies were performed before (left panels) and after (right panels) 4 months of treatment with pioglitazone (a) or metformin (b). ${ }^{*} p<0.05$, $* * p<$ 0.01 vs glycerol study day; ${ }^{\dagger} p<0.05,{ }^{\star} p<0.01$ 

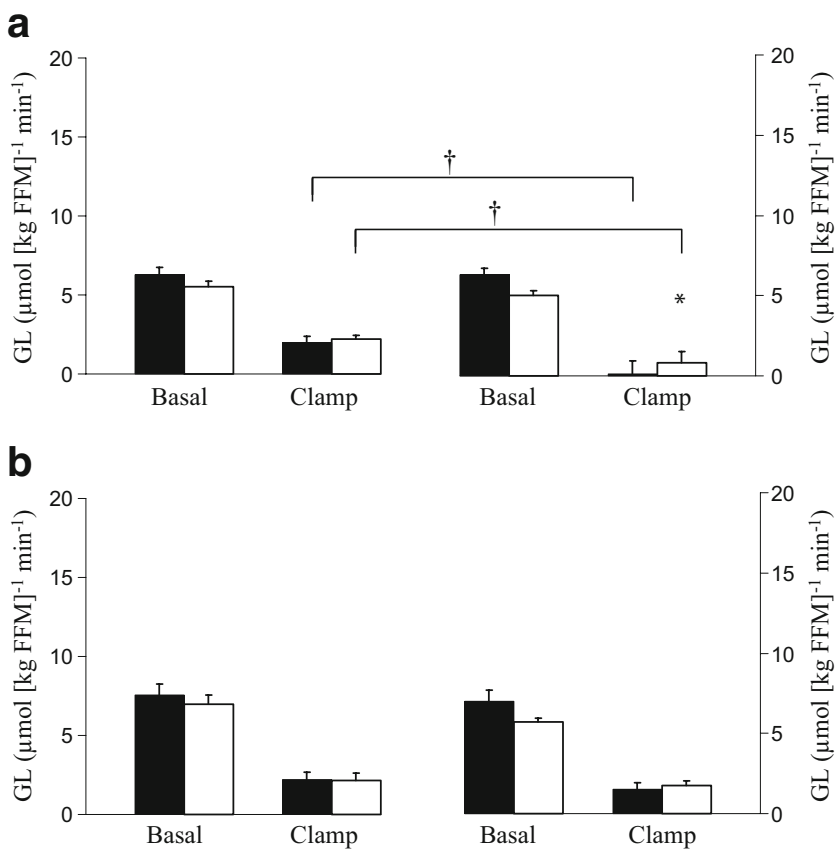

Fig. 6 Rates of glycogenolysis (GL) before (basal) and during (clamp) a hyperinsulinaemic-euglycaemic clamp during infusion of Intralipid and heparin (white bars) or glycerol (black bars). Studies were performed before (left panels) and after (right panels) 4 months of treatment with pioglitazone (a) or metformin (b). ${ }^{*} p<0.05$ vs glycerol study day; ${ }^{\dagger} p<0.05$

that observed in the absence of elevated NEFA, both before and after treatment with pioglitazone. Previous studies have reported that treatment of rodents with a thiazolidinedione increases glucose disposal during lipid infusion to rates observed prior to treatment with a thiazolidinedione in the absence of a lipid infusion [4, 16, 17]. The same pattern was observed in the present studies. Rates of glucose disappearance during the $\mathrm{IL} / \mathrm{H}$ infusion following treatment with pioglitazone did not differ from those observed in the same individuals during the glycerol infusion prior to treatment with pioglitazone. In addition, rates of glucose production were lower on the $\mathrm{IL} / \mathrm{H}$ study day after treatment with pioglitazone than they were on the glycerol study before treatment with pioglitazone. If glycerol control studies had not been performed both before and after treatment, these data could have been interpreted erroneously as indicating that pioglitazone protected against NEFA-induced insulin resistance. However, rates of glucose disappearance continued to be lower and glucose production higher during the clamps on the IL/H study day than on the glycerol study day after treatment. This indicates that, whereas pioglitazone improved insulin action, it did not prevent NEFA-induced hepatic or extrahepatic insulin resistance in people with type 2 diabetes. This conclusion is consistent with the results of Serlie et al. [19], who reported that glucose disappearance was lower and glucose production slightly (but not significantly) higher during an Intralipid infusion than during a saline infusion following 4 months of treatment of eight type 2 diabetic patients with pioglitazone. They are also consistent with the report by Dhindsa et al. [18] that the glucose infusion rate required to maintain euglycaemia in obese non-diabetic participants was decreased during a lipid infusion both before and after 6 weeks of treatment with rosiglitazone.

Glucose production equals the sum of gluconeogenesis and glycogenolysis. Rates of gluconeogenesis during the clamps were lower after than before treatment with pioglitazone on both the $\mathrm{IL} / \mathrm{H}$ and the glycerol study day. This observation is consistent with previous reports that thiazolidinediones enhance insulin-induced suppression of gluconeogenesis [20, 26-29]. Rates of glycogenolysis during the clamp were also lower after than before treatment on both the IL/H and the glycerol study day, indicating that pioglitazone also enhanced insulin-induced suppression of glycogenolysis. However, as with the overall rate of glucose production, rates of gluconeogenesis and glycogenolysis were higher after treatment with pioglitazone on the $\mathrm{IL} / \mathrm{H}$ than on the glycerol study day. Thus, while treatment with pioglitazone improved insulin-induced suppression of gluconeogenesis and glycogenolysis, it did not prevent NEFA-induced inhibition of these processes.

Effects of metformin on NEFA-induced insulin resistance We are unaware of any studies that have specifically examined the ability of metformin to prevent NEFA-induced insulin resistance in people with type 2 diabetes. In the present study, glucose disappearance was lower during the clamp on the IL/H than on the glycerol study day before but not after treatment with metformin, indicating that metformin protected against NEFA-induced extrahepatic insulin resistance. However, metformin did not protect against hepatic insulin resistance since glucose production during the clamp remained higher on the $\mathrm{IL} / \mathrm{H}$ than on the glycerol study day.

Metformin has been reported to increase fat oxidation, fat clearance, insulin signalling and stimulation of AMP kinase in muscle [5, 6, 30-35]. Therefore protection against NEFA-induced resistance in extrahepatic tissues, presumably including muscle, is not surprising. On the other hand, the higher rates of glucose production in the presence of elevated NEFA following treatment with metformin were unanticipated. Previous studies have reported that metformin lowers fasting glucose concentrations primarily by lowering fasting glucose production, presumably by lowering gluconeogenesis [1, 36-38]. However, metformin treatment resulted in a substantial improvement in glycaemic control in those experiments. We and others have shown that any treatment (e.g. sulfonylureas or insulin) that improves glycaemic control lowers fasting glucose production and improves hepatic insulin action [39, 40]. In the 
present studies, chronic glycaemic control did not improve and, if anything, deteriorated slightly $(\sim 0.3 \%$ increase in $\mathrm{HbA}_{1 \mathrm{c}}$ ) following treatment with metformin. Under these conditions, the insulin-induced suppression of both overall glucose production and gluconeogenesis on the IL/H study day remained impaired relative to that observed on the glycerol study day following treatment with metformin. In addition, rates of gluconeogenesis on the $\mathrm{IL} / \mathrm{H}$ study day were higher after than before treatment, suggesting that, if anything, metformin exacerbated rather than protected against NEFA-induced hepatic insulin resistance. Future studies examining the mechanism(s) by which metformin protects against NEFA-induced insulin resistance in muscle but not the liver will be of considerable interest.

Limitations The plasma NEFA concentration was slightly lower after treatment than before treatment despite empirically increasing the rate of $\mathrm{IL} / \mathrm{H}$ infusion by approximately $30 \%$. This could have been a result of increased clearance, reduced spillover and/or reduced endogenous lipolysis [9, $41,42]$.Therefore, the inhibitory effects of NEFA on insulin action may have been greater if NEFA concentrations following treatment with pioglitazone had been even higher on the IL/H study day. In addition, the apparent improvement in insulin action in the presence of elevated NEFA after compared with before treatment with pioglitazone could have been due, at least in part, to the slightly lower plasma NEFA concentration. The observation that the increment in glucose disappearance during the clamp following treatment with pioglitazone was correlated with the decrement in NEFA on the IL/H study day $(r=0.76, p<0.01)$ supports this possibility. Gluconeogenesis was measured using the ${ }^{2} \mathrm{H}$-labelled water method. The limitations of this method, including the assumption that little, if any, ${ }^{2} \mathrm{H}$ is incorporated onto the fifth carbon of glucose via the transaldolase reaction, have been discussed in detail [43, 44]. We do not know whether this assumption also holds during treatment with pioglitazone or metformin.

Insulin was infused overnight to ensure that glucose concentrations were similar on all occasions. While this may have improved insulin action by reducing 'glucotoxicity' [45], it did not prevent NEFA-induced insulin resistance and cannot explain the differences in the effects of NEFA on insulin action following treatment with pioglitazone compared with treatment with metformin, since glucose concentrations were comparable on all occasions. On the other hand, since glucose concentrations were relatively well controlled in the present participants, it is not known whether these results pertain to individuals with poor glycaemic control and markedly elevated fasting glucose concentrations. With the continued focus on improving glycaemic control, such individuals may become less common. The conclusions of the current report are based on paired pre- and post-treatment data available in 20 participants. However, as noted in the Methods section, although 31 participants entered the study, pretreatment data were not available in 11 participants because of technical problems. However, the conclusions were the same (i.e. metformin but not pioglitazone protects against NEFA-induced extrahepatic insulin resistance, whereas neither agent protects against NEFA-induced hepatic insulin resistance) when the post-treatment data (available in all 31 participants) were analysed separately (data not shown). Consistent with previous studies [5, 17-19, 46-50] plasma NEFA concentrations were acutely (i.e. for $9 \mathrm{~h}$ ) increased by infusion of a lipid emulsion mimicking the changes that commonly occur during the night or in the late postprandial setting [11, 51]. Additional studies will be required to determine whether pioglitazone and metformin have comparable effects in the presence of chronically (i.e. days to months) elevated NEFA.

Conclusions The present data indicate that neither thiazolidinediones nor metformin fully protect against NEFAinduced insulin resistance. When compared with pretreatment values, pioglitazone increased insulin action in the presence of elevated NEFA. However, insulin-induced stimulation of glucose disappearance and suppression of glucose production, gluconeogenesis and glycogenolysis continued to be impaired relative to that observed in the absence of elevated NEFA, indicating the persistence of NEFA-induced hepatic and extrahepatic insulin resistance. In contrast, whereas metformin enhanced insulin-induced stimulation of glucose disappearance in the presence of elevated NEFA and protected against NEFA-induced extrahepatic insulin resistance, it did not prevent NEFAinduced hepatic insulin resistance. Taken together, these data indicate that while both thiazolidinediones and metformin increase insulin action in the presence of elevated NEFA, their effects on NEFA-induced insulin resistance in liver and muscle differ, perhaps explaining, at least in part, why treatment of people with type 2 diabetes with a combination of these drugs results in a greater improvement in glycaemic control than does treatment with either agent alone.

Acknowledgements This study was supported by the US Public Health Service (DK29953, DK14507, RR-00585, U 54RR 24150-1) and a Merck research infrastructure grant. We wish to thank G. DeFoster, P. Reich and P. Helwig for technical assistance, M. Le, M. Davis and C. Nordyke (Mayo Clinic) for assistance with preparation of the manuscript and the staff of the Mayo Clinical Research Unit and Center for Clinical and Translation Science Activities for assistance with the studies. We also thank Takeda Pharmaceuticals North America for provision of pioglitazone. Takeda Pharmaceuticals did not contribute to the study design, execution, data collection, analysis or preparation of the manuscript. 
Duality of interest The authors declare that there is no duality of interest associated with this manuscript.

\section{References}

1. Kerpichnikov D, McFarlane SI, Sowers JR (2002) Metformin: an update. Ann Intern Med 137:25-33

2. Nathan DM (2002) Initial management of glycemia in type 2 diabetes mellitus. N Engl J Med 347:1342-1349

3. Inzucchi SE (2002) Oral antihyperglycemic therapy for type 2 diabetes: scientific review. JAMA 287:360-372

4. Ye J-M, Dzamko N, Cleasby ME et al (2004) Direct demonstration of lipid sequestration as a mechanism by which rosiglitazone prevents fatty-acid-induced insulin resistance in the rat: comparison with metformin. Diabetologia 47:1306-1313

5. Cleasby ME, Dzamko N, Hegarty BD, Cooney GJ, Kraegen EW, Ye J-M (2004) Metformin prevents the development of acute lipid-induced insulin resistance in the rat through altered hepatic signaling mechanisms. Diabetes 53:3258

6. Collier CA, Bruce CR, Smith AC, Lopaschuk G, Dyck DJ (2006) Metformin counters the insulin-induced suppression of fatty acid oxidation and stimulation of triacylglycerol storage in rodent skeletal muscle. Am J Physiol Endocrinol Metab 291:E182-E189

7. Todd MK, Watt MJ, Le J, Hevener AL, Turcotte LP (2007) Thiazolidinediones enhance skeletal muscle triacylglycerol synthesis while protecting against fatty acid-induced inflammation and insulin resistance. Am J Physiol Endocrinol Metab 292:E485-E493

8. Mayerson AB, Hundal RS, Dufour S et al (2002) The effects of rosiglitazone on insulin sensitivity, lipolysis, and hepatic and skeletal muscle triglyceride content in patients with type 2 diabetes. Diabetes 51:797-802

9. Miyazaki Y, Glass L, Triplitt C et al (2001) Effect of rosiglitazone on glucose and non-esterified fatty acid metabolism in type II diabetic patients. Diabetologia 44:2210-2219

10. Tiikkainen M, Tamminen M, Häkkinen A-M et al (2002) Liver-fat accumulation and insulin resistance in obese women with previous gestational diabetes. Obes Res 10:859-867

11. Miles JM, Wooldridge D, Grellner WJ et al (2003) Nocturnal and postprandial free fatty acid kinetics in normal and type 2 diabetic subjects: effects of insulin sensitization therapy. Diabetes 52:675681

12. Tonelli J, Li W, Kishore P et al (2004) Mechanisms of early insulin-sensitizing effects of thiazolidinediones in type 2 diabetes. Diabetes 53:1621-1629

13. Maggs DG, Buchanan TA, Burant CF et al (1998) Metabolic effects of troglitazone monotherapy in type 2 diabetes mellitus: a randomized, double-blind, placebo-controlled trial. Ann Intern Med 128:176-185

14. Virtanen KA, Hällstenh K, Parkkola R et al (2003) Differential effects of rosiglitazone and metformin on adipose tissue distribution and glucose uptake in type 2 diabetic subjects. Diabetes 52:283-290

15. Boden G, Cheung P, Mozzoli M, Fried SK (2003) Effects of thiazolidinediones on glucose and fatty acid metabolism in patients with type 2 diabetes. Metabolism 52:753-759

16. Hevener AL, Reichart D, Janez A, Olefsky J (2001) Thiazolidinedione treatment prevents free fatty acid-induced insulin resistance in male Wistar rats. Diabetes 50:2316-2322

17. Ye J-M, Frangioudakis G, Iglesias MA et al (2002) Prior thiazolidinedione treatment preserves insulin sensitivity in normal rats during acute fatty acid elevation: role of the liver. Endocrinology 143:4527-4535

18. Dhindsa S, Tripathy D, Sanalkumar N et al (2005) Free fatty acidinduced insulin resistance in the obese is not prevented by rosiglitazone treatment. J Clin Endocrinol Metab 90:5058-5063
19. Serlie MJ, Allick G, Groener JE et al (2007) Chronic treatment with pioglitazone does not protect obese patients with diabetes mellitus type II from free fatty acid-induced insulin resistance. J Clin Endocrinol Metab 92:166-171

20. Basu R, Shah P, Basu A et al (2008) Comparison of the effects of pioglitazone and metformin on hepatic and extra-hepatic insulin action in people with type 2 diabetes. Diabetes 57:24-31

21. Schumann WC, Gastaldelli A, Chandramouli V et al (2001) Determination of the enrichment of the hydrogen bound to carbon 5 of glucose on $2 \mathrm{H}_{2} \mathrm{O}$ administration. Anal Biochem 297:195-197

22. Miles J, Glasscock R, Aikens J, Gerich J, Haymond M (1983) A microfluorometric method for the determination of free fatty acids in plasma. J Lipid Res 24:96-99

23. Steele R, Wall J, DeBodo R, Altszuler N (1956) Measurement of size and turnover rate of body glucose pool by the isotope dilution method. Am J Physiol 187:15-24

24. Basu R, Chandramouli V, Dicke B, Landau B, Rizza R (2005) Obesity and type 2 diabetes impair insulin-induced suppression of glycogenolysis as well as gluconeogenesis. Diabetes 54:19421948

25. Tiikainen M, Hakkinen A-M, Korsheninnikova E, Nyman T, Makimattila S, Yki-Jarvinen H (2004) Effects of rosiglitazone and metformin on liver fat content, hepatic insulin resistance, insulin clearance, and gene expression in adipose tissue in patients with type 2 diabetes. Diabetes 53:2169-2176

26. Gastaldelli A, Miyazaki Y, Mahankali A et al (2006) The effect of pioglitazone on the liver: role of adiponectin. Diabetes Care 29:2275-2281

27. Gastaldelli A, Miyazaki Y, Pettiti M et al (2006) The effect of rosiglitazone on the liver: decreased gluconeogenesis in patients with type 2 diabetes. J Clin Endocrinol Metab 91:806-812

28. Davies GF, Khandelwal RL, Wu L, Juurlink BHJ, Roesler WJ (2001) Inhibition of phosphoenolpyruvate carboxykinase (PEPCK) gene expression by troglitazone: a peroxisome proliferator-activated receptor-g (PPARg)-independent, antioxidant-related mechanism. Biochem Pharmacol 62:1071-1079

29. Fulgencio J-P, Kohn C, Girard J, Pégorier J-P (1996) Troglitazone inhibits fatty acid oxidation and esterification, and gluconeogenesis in isolated hepatocytes from starved rats. Diabetes 45:1556-1562

30. Grosskopf I, Ringel Y, Charach G et al (1997) Metformin enhances clearance of chylomicrons and chylomicron remnants in nondiabetic mildly overweight glucose-intolerant subjects. Diabetes Care 20:1598-1602

31. Song S, Andrikopoulos S, Filippis C, Thorburn AW, Khan D, Proietti J (2001) Mechanism of fat-induced hepatic gluconeogenesis: effect of metformin. Am J Physiol Endocrinol Metab 281:E275-E282

32. Zhou G, Myers R, Li Y et al (2001) Role of AMP-activated protein kinase in mechanism of metformin action. J Clin Invest 108:1167-1174

33. Del Prato S, Marchetto S, Pipitone A, Zanon M, de Kreutzenberg S, Tiengo A (1995) Metformin and free fatty acid metabolism. Diabetes Metab Rev 11:S33-S41

34. Dominguez LJ, Davidoff AJ, Srinivas PR, Standley PR, Walsh MF, Sowers JR (1996) Effects of metformin on tyrosine kinase activity, glucose transport, and intracellular calcium in rat vascular smooth muscle. Endocrinology 137:113-121

35. Gunton JE, Delhanty PJD, Takahashi S-I, Baxter RC (2003) Metformin rapidly increases insulin receptor activation in human liver and signals preferentially through insulin-receptor substrate2. J Clin Endocrinol Metab 88:1323-1332

36. Hundal RS, Krssak M, Dufour S et al (2000) Mechanism by which metformin reduces glucose production in type 2 diabetes. Diabetes 49:2063-2069

37. Stumvoll M, Nurjhan N, Perriello G, Dailey G, Gerich JE (1995) Metabolic effects of metformin in non-insulin-dependent diabetes mellitus. N Engl J Med 333:550-554 
38. Natali A, Ferrannini E (2006) Effects of metformin and thiazolidinediones on suppression of hepatic glucose production and stimulation of glucose uptake in type 2 diabetes: a systematic review. Diabetologia 49:434-441

39. Simonson DC, Ferrannini E, Bevilacqua S et al (1984) Mechanism of improvement in glucose metabolism after chronic glyburide therapy. Diabetes 33:838-845

40. Firth R, Bell P, Marsh M, Rizza RA (1987) Effects of tolazamide and exogenous insulin on pattern of postprandial carbohydrate metabolism in patients with non-insulin-dependent diabetes mellitus. Diabetes 36:1130-1138

41. Tan GD, Fielding BA, Currie JM et al (2005) The effects of rosiglitazone on fatty acid and triglyceride metabolism in type 2 diabetes. Diabetologia 48:83-95

42. van Wijk JP, de Koning EJ, Castro Cabezas M, Rabelink TJ (2005) Rosiglitazone improves postprandial triglyceride and free fatty acid metabolism in type 2 diabetes. Diabetes Care 28:844849

43. Landau BR, Wahren J, Chandramouli V, Schumann WC, Ekberg $\mathrm{K}$ (1995) Use of $2 \mathrm{H} 2 \mathrm{O}$ for estimating rates of gluconeogenesis: application to the fasted state. J Clin Invest 95:172-178

44. Bock G, Schumann WC, Basu R et al (2008) Evidence that processes other than gluconeogenesis may influence the ratio of deuterium on the fifth and third carbons of glucose: implications for the use of $2 \mathrm{H}_{2} \mathrm{O}$ to measure gluconeogenesis in humans. Diabetes 57:50-55

45. Yki-Jarvinen H (1992) Glucose toxicity. Endocr Rev 13:415-431

46. Roden M, Stingl H, Chandramouli V et al (2000) Effects of free fatty acid elevation on postabsorptive endogenous glucose production and gluconeogenesis in humans. Diabetes 49:701707

47. Clore JN, Glickman PS, Nestler JE, Blackard WG (1991) In vivo evidence for hepatic autoregulation during NEFA-stimulated gluconeogenesis in normal humans. Am J Physiol 261:E425-E429

48. Lam TKT, Carpentier A, Lewis GF, Van De Werve G, Fantus IG, Giacca A (2003) Mechanisms of the free fatty acid-induced increase in hepatic glucose production. Am J Physiol Endocrinol Metab 284:E863-E873

49. Chen X, Iqbal N, Boden G (1999) The effects of free fatty acids on gluconeogenesis and glycogenolysis in normal subjects. J Clin Invest 103:365-372

50. Boden G, Cheung P, Stein TP, Kresge K, Mozzoli M (2002) NEFA cause hepatic insulin resistance by inhibiting insulin suppression of glycogenolysis. Am J Physiol Endocrinol Metab 283:E12-E19

51. Kim SP, Catalano KJ, Hsu IR, Chiu JD, Richey JM (2007) Nocturnal free fatty acids are uniquely elevated in the longitudinal development of diet-induced insulin resistance and hyperinsulinemia. Am J Physiol Endocrinol Metab 292:E1590-E1598 